\title{
Gulf War Illness-associated increases in blood levels of interleukin 6 and C-reactive protein: biomarker evidence of inflammation
}

\author{
Tammy A. Butterick ${ }^{1,2}$, Janeen H. Trembley 1,3,4, Laura L. Hocum Stone ${ }^{1,5}$, Clemma J. Muller ${ }^{6}$, \\ Rebecca R. Rudquist ${ }^{1}$ and Ronald R. Bach ${ }^{1,7^{*}}$ (D)
}

\begin{abstract}
Objective: Gulf War Illness is a chronic multisymptom disorder severely impacting the health and well-being of many Veterans of the 1990-1991 Gulf War. Symptoms that define the disease include pain, fatigue, mood and memory impairments, gastrointestinal problems, lung disorders, and skin rashes. In our previous biomarker study, we discovered Gulf War Illness-associated proinflammatory blood biomarkers. Therefore, we hypothesized that chronic inflammation causes the symptoms that define this disorder. Testing the chronic inflammation hypothesis is the objective of this study.

Results: The biomarker fingerprint of Gulf War Illness is the end-product of a cascade of proinflammatory cytokine signals. In particular, the observed increase in C-reactive protein predicts a corresponding increase in interleukin 6, the cytokine that stimulates hepatocytes to produce C-reactive protein. Therefore, in this study we measured potential upstream cytokine signals in plasma samples from Gulf War Veterans. As predicted, a positive correlation between interleukin 6 and C-reactive protein was observed.
\end{abstract}

Keywords: Gulf War Illness, Chronic multisymptom illness, Chronic inflammation, Biomarkers, Proinflammatory cytokines, Interleukin 6, C-reactive protein, Case-control study

\section{Introduction}

From August 2, 1990 to July 31, 1991, nearly 700,000 US military personnel served in the First Gulf War, Operations Desert Shield and Desert Storm. Now, many of these Gulf War Veterans suffer from an unexplained chronic multisymptom illness (CMI). A 2014 report from National Academy of Sciences Institute of Medicine to the Department of Veterans Affairs (VA) recommended the name should be changed from CMI to Gulf War illness (GWI) [1]. Another recommendation in the same report was the use of either the Kansas or the Centers for Disease Control and

${ }^{*}$ Correspondence: Ronald.Bach@VA.gov

${ }^{1}$ Minneapolis Veterans Affairs Health Care System, Minneapolis, MN, USA

Full list of author information is available at the end of the article
Prevention (CDC) case definitions for GWI $[2,3]$. They noted the symptomatic criteria defining this syndrome are well characterized by both case definitions. There are six GWI-associated symptom domains: (1) fatigue/sleep problems, (2) pain (musculoskeletal), (3) mood-cognition, (4) gastrointestinal, (5) pulmonary, and (6) skin (rashes). The high prevalence of these symptoms amongst Gulf War Veterans makes GWI the signature adverse health-related outcome of the 1990-1991 Gulf War [2-6].

The accurate diagnosis and effective treatment of GWI require a detailed understanding of the underlying disease. The lack of information about GWI pathophysiology led us to initiate a search for objective biomarkers to augment current symptomatic diagnostic criteria. In our case-control observational study we identified 11 blood 
biomarker differences between symptomatic (GWI+) and asymptomatic (GWI-) Gulf War Veterans [7].

Plasma proteomics identified 6 biomarker differences., and blood cell enumeration identified 5 biomarker differences. All 11 GWI-associated blood biomarker differences are potential indicators of inflammation. In particular, there was the GWI-associated increase in C-reactive protein (CRP). CRP is a well-established biomarker of inflammation produced by hepatocytes. A pro-inflammatory cytokine cascade involving both interleukin 1 beta (IL-1 $\beta$ ) and interleukin 6 (IL-6) is the signal stimulating CRP gene expression. The initial biomarker study did not yield useful data for either IL-1 $\beta$ or IL-6. We hypothesized that a more sensitive cytokine immunoassay would reveal GWI-associated proinflammatory cytokine increases. This evidence would support our hypothesis that chronic inflammation is the underlying cause of GWI-associated symptoms.

\section{Main text Methods}

In the current study, pro-inflammatory cytokine levels were measured in plasma samples from the parent study entitled "Biomarkers of Gulf War Veterans' Illnesses: Tissue Factor, Chronic Coagulopathy, and Inflammation." Gulf War Veterans entered the case-control observational human study between 2010 and 2013. The Veterans were interviewed in person, and written informed consent was obtained. Health status was assessed via a structured interview, and blood samples were obtained.

The only inclusion criteria for Veterans enrolled in this study were honorable discharge from US military service and deployment to the Kuwaiti Theater of Operations during the 1990-1991 Gulf War. Exclusion criteria included history of cancer, liver disease, acute or chronic inflammatory states, or other major chronic illness such as chronic fatigue syndrome and fibromyalgia that could be associated with inflammation. Post-traumatic stress disorder did not exclude subjects.

All subjects completed a symptom questionnaire, the CDC 10 question symptoms assessment survey (CDC10), for CMI developed by Fukuda et al. [3]. This survey included three categories and nine subcategories: (1) fatigue; (2) mood-cognition (depression, anxiety, moodiness, memory problems, difficulty with words, difficulty sleeping); and (3) musculoskeletal (muscle pain, joint pain, and joint stiffness). Subjects were considered to have GWI and were classified as GWI+ if: (a) they had one or more chronic symptoms from at least 2 of 3 of the case-defining symptom categories-fatigue, mood-cognition, and musculoskeletal pain; (b) the symptoms began during or after the 1990-1991 Gulf War; and (c) symptoms were present for at least 6 months. Subjects without case-defining symptoms or a symptom in only one category were considered not to have GWI and were classified as GWI-.

Plasma samples were obtained as described [7]. Briefly, non-fasting, peripheral venous blood was collected into $4.0 \mathrm{ml}$ Vacutainer1 vacuum tubes (BD, Franklin Lakes, NJ, USA) containing $7.2 \mathrm{mg}$ K2 EDTA. Platelet-poor plasma was isolated from whole blood by centrifugation at $1770 \times g$ for $15 \mathrm{~min}$ at room temperature. The plasma layer was carefully removed and centrifuged at $1770 \times g$ for 15 min until the platelet count was $\leq 1 / \mu \mathrm{l}$ (Beckman Coulter AcTdiff 2 counter, Brea, CA, USA). Plasma aliquots were snap frozen on dry ice and stored at $-80^{\circ} \mathrm{C}$.

We employed the Meso Scale Discovery (MSD) (Rockville, MD, USA) plate-based electrochemiluminescence (ECL) assay platform to quantify plasma concentrations of interferon gamma (IFN- $\gamma$ ), IL-1 $\beta$, interleukin 2 (IL-2), interleukin 4 (IL-4), IL-6, interleukin 8 (IL-8), interleukin 10 (IL-10), interleukin 12 p70 (IL-12 p70), interleukin 13 (IL-13), and tumor necrosis factor alpha (TNF- $\alpha$ ). Stored plasmas from the initial GWI biomarker study were assayed [7]. Plasma aliquots were thawed on wet ice just prior to use, diluted 1:2 using Diluent 2, and each sample was run in duplicate by loading $50 \mu$ of diluted plasma samples into the wells. The V-PLEX Human Proinflammatory Panel 1 Human Biomarker 40-Plex Kit was used. Plates were processed according to the manufacturer's instructions and read using the MSD MESO Sector $\mathrm{S} 600$ instrument. The assay data were analyzed using MSD Discovery Workbench 4.0 software and exported to an Excel spreadsheet for further analysis. Table 1 list the number of samples for each cytokine with analyte levels above the lowest levels of detection (LLOD). Cytokines with any samples below the LLOD were excluded from further analysis. The average signal covariance of

Table 1 Total number of cytokine values above the LLOD in each CRP quartile

\begin{tabular}{lllllllllll}
\hline CRP quartiles & IFN- $\boldsymbol{\gamma}$ & IL-1 $\boldsymbol{\beta}$ & IL-2 & IL-4 & IL-6 & IL-8 & IL-10 & IL-12p70 & IL-13 & TNF-a \\
\hline Q1 & 20 & 7 & 13 & 20 & 20 & 20 & 20 & 20 & 12 & 20 \\
Q2 & 20 & 8 & 3 & 10 & 20 & 20 & 20 & 14 & 4 & 20 \\
Q3 & 20 & 5 & 2 & 12 & 20 & 20 & 20 & 16 & 5 & 20 \\
Q4 & 20 & 9 & 16 & 20 & 20 & 20 & 20 & 20 & 18 & 20 \\
\hline
\end{tabular}


Table 2 Plasma biomarker distributions in $\mathrm{GWI}+$ and GWI- Veterans

\begin{tabular}{llll}
\hline Biomarker & GWI+ $(\mathbf{n}=\mathbf{5 3})$ & GWI- $(\mathbf{n}=\mathbf{2 7})$ & P-value* $^{*}$ \\
\hline $\mathrm{IL}-6, \mathrm{pg} / \mathrm{ml}$ & $0.80(0.58-1.37)^{\mathrm{a}}$ & $0.64(0.50-0.93)$ & 0.08 \\
$\mathrm{IFN}-\mathrm{\gamma}, \mathrm{pg} / \mathrm{ml}$ & $2.32(1.69-3.45)$ & $3.32(1.77-5.86)$ & 0.30 \\
$\mathrm{IL}-10, \mathrm{pg} / \mathrm{ml}$ & $0.21(0.17-0.30)$ & $0.24(0.18-0.36)$ & 0.43 \\
$\mathrm{TNF}-\mathrm{a}, \mathrm{pg} / \mathrm{ml}$ & $2.14(1.93-2.47)$ & $2.22(1.92-2.58)$ & 0.56 \\
$\mathrm{IL}-8, \mathrm{pg} / \mathrm{ml}$ & $4.43(3.20-5.33)$ & $3.84(2.79-6.24)$ & 0.94 \\
\hline
\end{tabular}

* Mann-Whitney test

a Median (interquartile)

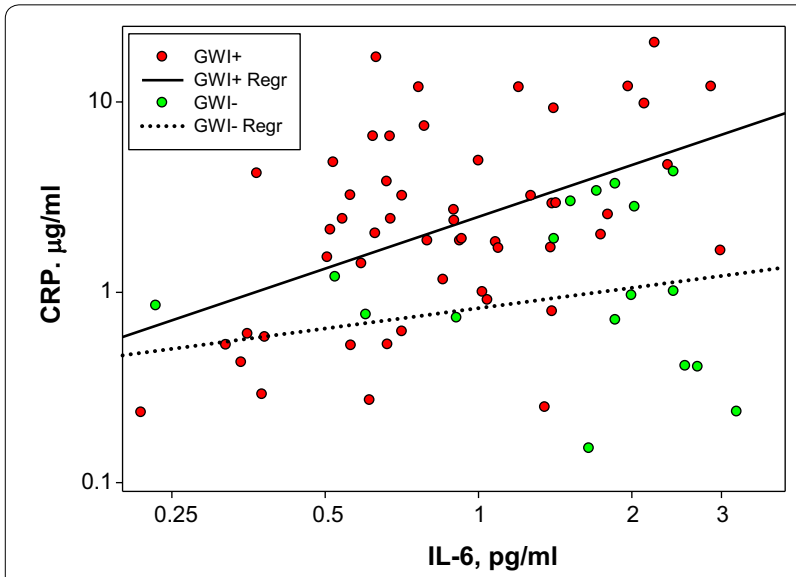

Fig. 1 Plasma IL-6 versus Plasma CRP. The scatter plot represents the plasma IL- 6 and CRP levels for each subject. The lines are the linear regression determinations for the $\mathrm{GWI}+$ and $\mathrm{GWI}-$ groups. $\mathrm{R}^{2}$ values for the regressions were $0.22^{\mathrm{GWI}+}$ and $0.15^{\mathrm{GWI}-}$

standards was $3.6 \%$, and the average calculated concentration covariance within the detection range of the assays was $4.4 \%$. The dynamic range was 3 logs for all assays.

Data calculations, Table 2, were performed using SigmaPlot (Version 11). There were no corrections for potential confounders. Data were graphed on a $\log _{10}-\log _{10}$ scale, Fig. 1. SigmaPlot (Version 11) was used for both the scatter plot and the linear regression calculations.

\section{Results}

In this study, stored plasma samples from our previous GWI blood biomarker study [7] were reanalyzed using a more sensitive immunoassay system. Samples were obtained from Veterans who were deployed during the Gulf War and classified as either GWI+ or GWIaccording to the CDC 10 case definition. The objective was to measure the plasma concentrations of 10 inflammation-related cytokines not detected in the previous study. To this end the MSD V-PLEX Proinflammatory
Panel 1 , which is sensitive to sub $\mathrm{pg} / \mathrm{ml}$ cytokine concentrations, was employed.

Eighty plasma samples were assayed for 10 cytokines, and the raw signals were converted to analyte concentrations using the standard curves. For IL- $\beta$, IL-2, IL-4, IL-12 p70, and IL-13, multiple samples had concentrations that fell below the LLOD. Therefore, these cytokines were excluded from the analysis. Cytokine concentrations of IFN- $\gamma$, IL-6, IL-8, IL-10, and TNF- $\alpha$ were above the LLOD in all 80 plasma samples. Statistical analysis of these data is presented in Table 2. Differences in cytokine levels between the GWI + and GWI- were small. However, the GWI-associated increase in IL-6 approached statistical significance with a P-value of 0.08 . The precision of the sample measurement was excellent; the average signal $\mathrm{CV}$ was $5.9 \%$ and the average calculated concentration $\mathrm{CV}$ for the samples within the detection ranges of the assays was $13.3 \%$.

The apparent IL-6 increase in the GWI+ group prompted a closer look at the data. CRP concentrations from the previous analysis [7] were plotted versus IL-6 levels, Fig. 1. The GWI status for each data point is color coded as GWI+ (red) and GWI- (green). While there was considerable data scatter, as indicated by the linear regression $\mathrm{R}^{2}$ values $\left(0.22^{\mathrm{GWI}+}, 0.15^{\mathrm{GWI}-}\right)$, CRP clearly increases as a function of IL- 6 for both groups. The rate of the increase, i.e., the slope of the line $\left(0.90^{\mathrm{GWI}}\right.$, $0.36^{\mathrm{GWI}-}$ ), was 2.5 -fold greater for the GWI+ group.

\section{Discussion}

An ever-increasing number of Gulf War Veterans are suffering from GWI [4-6]. Studying underlying pathophysiology is the translational path to discovery of objective diagnostic measures and evidence-based treatments. Mindful of these goals, we tested the hypothesis that the GWI-associated chronic inflammation is driven by a cascade of proinflammatory cytokine signals. Measuring plasma levels of proinflammatory cytokines may provide direct evidence of an activated inflammatory cascade in GWI.

The GWI blood biomarkers detected in our initial study [7] are all related to inflammation. Also, inflammation can cause all the symptoms of GWI [8-15]. Thus, it is our assertion that chronic inflammation is the underlying cause of GWI symptoms. The biomarker evidence supports a molecular mechanism in which GWI begins with a pro-inflammatory stimulus. Immune cells respond to the stimulus by synthesizing pro-inflammatory cytokines that initiate the inflammatory cascade [16, 17]. Next, these primary cytokines act via autocrine, paracrine, and endocrine signaling pathways to alter gene expression and produce the GWI blood biomarker fingerprint. 
It is our contention that these blood-based phenotypic changes, induced by environmental toxins and stresses, are the systemic events that produce the cluster of symptoms we call GWI. In our model of GWI, there are three key steps: (1) The inflammatory cascade is triggered by toxic exposures and stresses such as those experienced by US military personnel in the Kuwaiti Theater of Operations. (2) The initial innate immune response is transformed into a chronic inflammatory state. (3) Chronic inflammation causes GWI-associated symptoms. The mechanism of the transition from an innate immune response to a chronic inflammatory state remains obscure, but this conversion is a potential high-value target for future interventions aimed at preventing chronic multisymptom illness.

The objective of the current study was to test the proinflammatory cytokine hypothesis. A major prediction, based on the results of the first study, is the GWI-associated increases in CRP are the result of increases in plasma IL-6 [18-20]. This objective was achieved by reanalyzing the stored plasma samples from the initial study with a more sensitive immunoassay system, the MSD-ECL platform. This system allowed us to measure $\mathrm{pg} / \mathrm{ml}$ plasma concentrations of 10 cytokines, and obtain new evidence demonstrating a positive correlation between plasma levels of CRP and IL-6. This result suggests that IL- 6 is a key proinflammatory signal driving the inflammatory cascade in GWI.

CRP gene expression is driven by IL- 6 , and IL- 6 gene expression is driven by IL- $1 \beta$. Our IL- $1 \beta$ data are limited by the fact that in 51 out of 80 samples the plasma level of IL-1 $\beta$ was below the LLOD. Thus, we cannot draw any direct conclusion about the role of IL- $1 \beta$ in GWI. The IL- 6 and CRP data indicate IL- $1 \beta$ is involved. However, direct evidence of a causal role for IL- $1 \beta$ in GWI must await a more sensitive assay.

Of note, median biomarker levels for the Veterans in this study with prevalent GWI were still within standard "normal" thresholds, and thus would not have been flagged by other studies that did not include a healthy control group. It is well established that inflammation increases with older age [21, 22], a phenomenon that could contribute to cumulative inflammatory burden and rising GWI incidence as this Veteran population ages.

We have presented evidence of a correlation between increased plasma levels of IL-6 and CRP in Gulf War Veterans. The rate of increase is greater for in the GWI+ group. This result support the conclusion of our previous blood biomarker study that low-grade chronic inflammation explains the high prevalence of GWI in Gulf War Veterans.

\section{Limitations}

- Small sample size (80 subjects).

- One-time sampling (not longitudinal).

- Small number of cytokines assayed [10].

- Complete data for only 5 of the cytokines.

\section{Abbreviations}

CDC: Centers for Disease Control and Prevention; CDC-10: CDC 10 question symptoms assessment survey; CMl: chronic multisymptom illness; CRP: C-reactive protein; GWI: Gulf War IIIness; GWI+: symptomatic Gulf War Veterans; GWI-: asymptomatic Gulf War Veterans; IFN-y: interferon gamma; IL-1 $\beta$ : interleukin 1 beta; IL-2: interleukin 2; LL-4: interleukin 4; IL-6: interleukin 6; IL-8: interleukin 8; IL-10: interleukin 10; IL-12: p70 interleukin 12 p70; IL-13: interleukin 13; LLOD: lowest levels of detection; MSD: Meso Scale Discovery; TNF-a: tumor necrosis factor alpha; VA: Department of Veterans Affairs.

\section{Acknowledgements}

The views expressed in this article are those of the authors and do not necessarily reflect the positions or policies of the US Department of Veterans Affairs or the US government.

\section{Authors' contributions}

TAB: data collection, data analysis, manuscript preparation. JHT: data collection, data analysis, manuscript preparation. LLHS: data analysis, manuscript preparation. CJM: data analysis, manuscript preparation. RRR: human studiesrelated activities, plasma sample acquisition and handling. RRB: human studies-related activities, plasma sample acquisition and handling, data collection, data analysis, manuscript preparation. All authors read and approved the final manuscript.

\section{Funding}

The author(s) disclosed receipt of the following financial support for the research, authorship, and/or publication of this article: Gulf War Illness Inflammation Reduction Trial (Department of Defense, Congressionally-Directed Medical Research Program, GW130025) and Biomarkers of Gulf War Veterans' Illnesses: Tissue Factor, Chronic Coagulopathy, and Inflammation (Department of Defense, Congressionally-Directed Medical Research Program, GW080080) to RRB. Dietary Fat Effect on Brain Immune Response and Inflammation (VA Merit Review, BX004146), Rodent model of systemic immune activation to study cognitive impairment in GulfWar illness (Center for Veterans Research and Education) and VA Shared Equipment Evaluation Program Request for a multi-array electrochemiluminescence biomarker assay reader (VA Merit Review, 1IS1BX004808-01) to TAB. VA Merit Review, 101 BX000760 to LHS.

\section{Availability of data and materials}

The datasets used and/or analysed during the current study are available from the corresponding author on reasonable request.

\section{Ethics approval and consent to participate}

All study subjects signed IRB-approved informed consent and HIPPA forms. The study was overseen by two IRBs: Human Studies Subcommittee of the Research and Development Committee of the Minneapolis VA Health Care System and the US Army Medical Research and Materiel Command Human Research Protection Office.

\section{Consent for publication}

Not applicable.

Competing interests

The authors declare that they have no competing interests.

\section{Author details}

${ }^{1}$ Minneapolis Veterans Affairs Health Care System, Minneapolis, MN, USA.

${ }^{2}$ Department of Food Science and Nutrition, University of Minnesota, St Paul, 
MN, USA. ${ }^{3}$ Masonic Cancer Center, University of Minnesota, Minneapolis, MN, USA. ${ }^{4}$ Department of Laboratory Medicine and Pathology, University of Minnesota, Minneapolis, MN, USA. ${ }^{5}$ Department of Surgery, University of Minnesota, Minneapolis, MN 55455, USA. ${ }^{6}$ Elson S Floyd College of Medicine, Washington State University, Spokane, WA, USA. ${ }^{7}$ Department of Medicine, University of Minnesota, Minneapolis, MN, USA.

Received: 15 October 2019 Accepted: 11 December 2019

Published online: 18 December 2019

\section{References}

1. National Academy of Sciences, Institute of Medicine. Committee on the development of a consensus case definition for chronic multisymptom illness in 1990-1991 Gulf War Veterans. Chronic multisymptom illness in Gulf War Veterans: case definitions reexamined. Washington, D.C.: National Academies Press. 2014; p. 90-9.

2. Steele L. Prevalence and patterns of Gulf War illness in Kansas veterans: association of symptoms with characteristics of person, place, and time of military service. Am J Epidemiol. 2000;152(10):992-1002.

3. Fukuda K, Nisenbaum R, Stewart G, Thompson WW, Robin L, Washko RM, et al. Chronic multisymptom illness affecting Air Force veterans of the Gulf War. JAMA. 1998;280(11):981-8.

4. Dursa EK, Barth SK, Schneiderman Al, Bossarte RM. Physical and mental health status of Gulf War and Gulf Era Veterans: results from a large population-based epidemiological study. J Occup Environ Med. 2016;58(1):41-6.

5. Blanchard MS, Eisen SA, Alpern R, Karlinsky J, Toomey R, Reda DJ, et al. Chronic multisymptom illness complex in Gulf War I veterans 10 years later. Am J Epidemiol. 2006;163(1):66-75.

6. Kang HK, Li B, Mahan CM, Eisen SA, Engel CC. Health of US veterans of 1991 Gulf War: a follow-up survey in 10 years. J Occup Environ Med. 2009;51(4):401-10.

7. Johnson GJ, Slater BC, Leis LA, Rector TS, Bach RR. Blood biomarkers of chronic inflammation in Gulf War Illness. PLoS ONE. 2016;1 1(6):e0157855.

8. Bourassa K, Sbarra DA. Body mass and cognitive decline are indirectly associated via inflammation among aging adults. Brain Behav Immun. 2017;60:63-70.

9. DeVon HA, Piano MR, Rosenfeld AG, Hoppensteadt DA. The association of pain with protein inflammatory biomarkers: a review of the literature. Nurs Res. 2014;63(1):51-62.
10. Kwekkeboom KL, Tostrud L, Costanzo E, Coe CL, Serlin RC, Ward SE, et al. The role of inflammation in the pain, fatigue, and sleep disturbance symptom cluster in advanced cancer. J Pain Symptom Manage. 2018;55(5):1286-95.

11. Nguyen $\mathrm{HQ}$, Herting JR, Pike KC, Gharib SA, Matute-Bello G, Borson S, et al. Symptom profiles and inflammatory markers in moderate to severe COPD. BMC Pulm Med. 2016;16(1):173.

12. Paulsen O, Laird B, Aass N, Lea T, Fayers P, Kaasa S, et al. The relationship between pro-inflammatory cytokines and pain, appetite and fatigue in patients with advanced cancer. PLoS ONE. 2017;12(5):e0177620.

13. Saglam Aykut D, Civil Arslan F, Ozkorumak Karaguzel E, Aral G, Karakullukcu S. The relationship between neutrophil-lymphocyte, plateletlymphocyte ratio and cognitive functions in bipolar disorder. Nord J Psychiatry. 2018;72(2):119-23.

14. Stringer EA, Baker KS, Carroll IR, Montoya JG, Chu L, Maecker HT, et al. Daily cytokine fluctuations, driven by leptin, are associated with fatigue severity in chronic fatigue syndrome: evidence of inflammatory pathology. J Transl Med. 2013;11:93.

15. Weinstein G, Lutski M, Goldbourt U, Tanne D. C-reactive protein is related to future cognitive impairment and decline in elderly individuals with cardiovascular disease. Arch Gerontol Geriatr. 2017;69:31-7.

16. Bohuon C. Inflammatory cascade response to toxin release: therapeutic perspectives. Ann Pharm Fr. 2001;59(3):191-7.

17. Dinarello CA. Proinflammatory cytokines. Chest. 2000;118(2):503-8.

18. Del Giudice M, Gangestad SW. Rethinking IL-6 and CRP: why they are more than inflammatory biomarkers, and why it matters. Brain Behav Immun. 2018;70:61-75.

19. Rossi JF, Lu ZY, Jourdan M, Klein B. Interleukin-6 as a therapeutic target. Clin Cancer Res. 2015;21(6):1248-57.

20. Sproston NR, Ashworth JJ. Role of C-reactive protein at sites of inflammation and infection. Front Immunol. 2018;9:754.

21. Sanada F, Taniyama Y, Muratsu J, Otsu R, Shimizu H, Rakugi H, et al. Source of chronic inflammation in aging. Front Cardiovasc Med. 2018;5:12.

22. Woods JA, Wilund KR, Martin SA, Kistler BM. Exercise, inflammation and aging. Aging Dis. 2012;3(1):130-40.

\section{Publisher's Note}

Springer Nature remains neutral with regard to jurisdictional claims in published maps and institutional affiliations.
Ready to submit your research? Choose BMC and benefit from:

- fast, convenient online submission

- thorough peer review by experienced researchers in your field

- rapid publication on acceptance

- support for research data, including large and complex data types

- gold Open Access which fosters wider collaboration and increased citations

- maximum visibility for your research: over 100M website views per year

At BMC, research is always in progress.

Learn more biomedcentral.com/submissions 